\title{
The Metrics of Ethics and the Ethics of Metrics
}

\author{
Gazi Islam ${ }^{1} \cdot$ Michelle Greenwood ${ }^{2}$
}

Accepted: 15 November 2021 / Published online: 25 November 2021

(c) The Author(s), under exclusive licence to Springer Nature B.V. 2021

\begin{abstract}
Metrics shape our social worlds in many and more ways. Everyday quantifications of our preferences, our behaviors and our relationships, alter us and the institutions that we constitute. This essay takes a brief look at the metrics of business ethics through two analytic devices. Representation explains the notion that metrics can capture or demonstrate ethics (the metrics of ethics) and performativity explains the notion that metrics can shape or constitute ethics (the ethics of metrics). The analytic distinction between representation and performativity is obscured in practice when metrics become targets, indeed much of the social power of metrics comes from their use as targets. Hence, we should pay attention to the world of practice in which measuring and doing are entangled. However, we should not lose sight of the limitations of measurement and the possibility that there are areas of ethical life best left unmeasured.
\end{abstract}

Keywords Metrics · Measurement · Quantification · Representation · Performativity · Audit society · Datafication

We live in a time in which measures and metrics have unprecedented importance in social life. From the daily public health briefings of pandemic illness tolls and vaccination rates, the measurement and reporting of climate emissions and biodiversity impacts, the inflation and bursting of economic bubbles in the financialized marketplace or the quantified selves made possible by digital technologies, social media and connected surveillance, technologies of measurement are increasingly woven into the fabric of social life. As these diverse social phenomena increasingly demand measurement (Islam, 2021), Business Ethics as a field is challenged to develop metrics that can adequately measure ethics, and to think through the ethics of how, when and with whom to construct such metrics. Conversely, business ethics scholarship, as much of social scientific scholarship generally, has been slow to pick up on the implications of metrics as themselves sources of ethical and social value, and

Gazi Islam

gazi.islam@grenoble-em.com

Michelle Greenwood

michelle.greenwood@monash.edu

1 Grenoble Ecole de Management and IREGE, Grenoble, France

2 Faculty of Business and Economics, Monash University, Melbourne, VIC, Australia as measurement as an ethically laden activity (cf., Järvinen et al., 2020, for a recent example).

Thus we see two interrelated concerns for business ethics research and practice posed by the demand to measure. The first of these challenges asks business ethicists to interrogate the sources of ethical value that should (or should not) be measured, and how such measurement can be done in way that ensures methodological rigor, epistemic validity, and social sensitivity. The demands a sensibility to what we call "the metrics of ethics". The second challenge asks of business ethicists that they consider metrics and measurement as forms of ethical (or unethical) action, and as technologies and institutionalized practices that have ethical ramifications and intervene in social life. This demands a sensibility to what we call "the ethics of metrics". In this editorial, we will examine each of these aspects of the social and ethical life of metrics and suggest directions in which business ethics can fruitfully develop ideas and practices for each.

\section{The Metrics of Ethics}

It is not new to the field that studying business ethics often requires measuring it. Particularly given the prominence of descriptive and empirical approaches to business ethics (cf., Ellertson et al., 2016), metrics have proliferated at all levels of the field, from psychometric scales, to measures 
of organizational-level sustainability and CSR, to alternative accounting and financial measurements. Often, as in the case of CSR, alternative metrics may compete to define a single construct, and the choice of metrics can shape the future of the field. As recent work has noted, however, the epistemological questions linked to such measures have ethical implications that are often left unexplored (Zyphur \& Pierides, 2017). Far from exhaustive, we briefly list three such implications.

First, and most intuitively, empirical business ethics research depends on our ability to measure ethical phenomena validly. Fair enough; but many validity criteria exist, and which should be privileged is not always clear. Classical validity categories such as face validity and content validity often invoke expert judgment, and in the realm of ethics, any such judgments involve attributions of expertise that are particularly difficult when compared to other social scientific disciples because of the overlay of descriptive and normative elements in such judgments. Specifically, while the descriptive component of ethical measure is subject to construct validation techniques that assess internal and external validity, the normative component is often left assumed. This is a concern that has been raised more broadly in previous editorials (Greenwood \& Freeman, 2017, 2018) and addressed more specifically in the context of social entrepreneurship in a recent paper (Bruder, 2020). One can test the construct validity of a behavioral scale, but the normative judgment regarding the behavior that the scale measures (e.g., the assumption that the construct measured by the scale labeled as "altruism" is necessarily good or virtuous) is not covered by classical validation theory. Zyphur and Pierides (2017) propose a new category of "relational" validity to mark the context-sensitivity of validity judgments, although recognizing the relational character cannot replace the hard work of justifying, each and every time, why a certain measure is used as it is. It may be that in the realm of ethics, there are no shortcuts for situated judgments.

Second, particularly in growing fields such as social and environmental reporting (cf., Cho \& Patten, 2013), measures characterize both academic work and in applied practice, where they are used for reporting and disclosure purposes. It is common for academics to adopt measures used by practitioners and vice versa, often without taking into account the unique settings in which metrics are designed, by whom and for what purposes (cf., Gilles, 2016). Sociologists of quantification have noted how metrics that were developed for one purpose often shift to different purposes (Desrosières, 1993); internal accounting figures become external benchmarks, feedback metrics become performance targets, and the like. A case in point is the MSCI KLD database that is used to measure corporate social responsibility. Although designed for business analyses, this database been used extensively in research, often only with brief mention of the strengths and weaknesses of using a practice tool for academic purposes (Mattingly \& Bailey, 2021; Harrison \& Berman, 2016). Without the proper reflexivity around our measures, we can easily lend an imprimatur of scientific validity to metrics that were designed for commercial purposes, or conversely, construct measures that are later deployed by private actors with unexpected social effects. In this context, it is important to consider the potential effects of "borrowing" company reported measures as academic data or of developing measures that could subsequently be used for purposes outside of the academy.

The above point does not suggest that such exchange is deleterious or should be avoided; on the contrary, it can be an important source of social relevance. Indeed, a developing agenda in business schools aims translate academic research into impact in business practice (e.g., Temple University's Fox School of Business in 2018 established a Translational Research Center that "strives to magnify the impact of the research"; https://www.fox.temple.edu/ institutes-centers/translational-research-center/). However, such exchange must be done reflexively, and the thought processes going into such choices should be articulated in the pages of the journal.

Third, measurement of ethical constructs in business ethics usually focuses on the core construct in question and rarely on what is not measured or taken into account in that measurement. Tacitly, each measurement presumes that a construct is ethically important in business and deserves to be measured, while focusing attention away from other competing ways of conceptualizing an ethical situation. For example, a scale measuring employee theft at work tacitly assumes (if correctly) that theft is wrong and should concern business ethicists, but may obscure background issues that are ethically relevant - why focus on employee and not employer theft, why are employees stealing rather than negotiating pay raises, what background conditions may make theft seem like the only or best option, etc. When we select a staring point for our research, we tend to inadvertently treat this as the starting point of the phenomenon or problem that we are attempting to address, as if the phenomenon and our relationship to it did not exist before we arrived. The social situatedness of our acts of measurement, as well as the social situatedness of who or what we are measuring, are a necessary part of any meaningful interpretation of measures. As a result, our choice of measures often reflects latent choices about whose interests are important and whose benefits should be safeguarded. As in the previous point, this is not necessarily to be avoided, but such choices should be articulated in a forthright manner. 


\section{The Ethics of Metrics}

The previous points focused on measurement aspects of ethics in their "representational" capacity-that is, how metrics selectively reflect aspects of reality in ways that can be partial, biased or misleading. Less common but increasingly pressing is scholarship around what can be termed the "performative" capacity of metrics-their ability to shape the world in their image and to bring new social realities into being (Islam, 2021). The representational and performative aspects of metrics are interlinked, and one may operate through the other. Yet, they are analytically distinct; considered as a representation, a metric should be revised when it does not fit the world, while considered as a performative, it is the world that is revised to fit the metric. Considered performatively, metrics are forms of action that themselves are ethically laden, given their ability to intervene into social processes and shape relations of social control (cf., Butler et al., 2020). Below, again not exhaustively, we note three ways in which the performativity of metrics is important in business ethics.

First, we lack robust discussion, within business ethics, of what metrics "do" and with what ethical consequences. The notion of performativity, that our knowledge, ideas, analytic tools, theories, and the like are not merely reflections of, but shape, our social world, is inspired by Austin's (1962) book "How to do things with words". While the performativity idea originally centered on language, examples of the performativity of numbers abound-performance appraisal systems that reconfigure personal relationships at work (Amiridis \& Costea, 2020); classification systems that decide the fate of refugees and asylum seekers (Ustek-Spilda, 2019); personal data that is re-tooled into credit scores that determine people's financial outcomes (Aitken, 2017); academic metrics that undermine scholarly values and discourage junior academics (Malsch \& Tessier, 2014). Accounting literature has for a long time recognized the "audit society" and its consequences (Power, 1997), and variations of these discussion are appearing in information sciences, finance, and sociology. There is growing interest with the heuristic of performativity in business ethics and corporate social responsibility, contributing to debates in areas such as intellectual capital measurement (Veltri \& Bronzetti, 2015), human resource management discourse (Greenwood \& Van Buren, 2017) and CSR theories (Marti \& Gond, 2018). Business ethics is uniquely poised to treat issues of performativity from an ethical point of view and add this crucial consideration to such discussions.

Second, the idea of metrics as performative opens up questions as to the multiplicity of different metrics and measures that pervade social life. Contemporary measurement scenarios often involve competing metrics around organizations and institutions-multiple bottom lines, diverse options for reporting social and environmental activity, competing journal rankings, a plethora of digital apps that quantify and classify in diverse ways. While some have bemoaned the hegemony of metrics in consolidating a field (Mingers \& Willmott, 2013), equally important are the ways in which diverse metric forms constituted performative struggles over how social life is to be objectified and counted (cf. Eccles et al., 2020). One consequence of such multiplicity is the emergence of forms of social activism based on rethinking metrics, from rethinking criminal statistics, to reformulating price indexes to better serve marginalized populations, to redefining health at work (cf., Bruno et al., 2014). In their book entitled "Good Data", Daly et al. (2019, p. 246) coined the term data activism as "an umbrella term which embraces, for instance, sociotechnical practices that provide counterhegemonic responses to the discrimination, social exclusion and privacy infringement that go hand in hand with big data". Less optimistically, Chandler and Fuchs (2019, p. 2) question if ubiquitous datafication of social knowledge may result in a digital positivism that threatens critique and "is likely to bring about the death of the social sciences and humanities". Understanding how metrics act in concert or against each other opens the way for a business ethics of metrics that takes into account multiple forms of classification and valuation, and the advent of a market for metrics.

Third, and relatedly, the performative aspect of metrics opens up questions around who is included and excluded in this performativity, both in terms of the researcher (who constructs and applies measures) and the researched (who is known through and undergoes measurement) and the artificial separation between the two. At this point it is helpful to remind ourselves that measurement is itself a social process; that the knowledge we create is constituted not only by what we measure but how we measure; that from the very outset of our research every decision we make and the conditions under which we make them have ethical implications. The aura of technical expertise around measurement, and the structural separation between who constructs metrics and who is measured by them, raises issues around voice, participation and democracy as measurement values. Recent analyses of the racial biases of algorithmic management (e.g., Martin, 2019; Noble, 2018), for example, are one example about how measures designed in non-participative ways can create unforeseen social harms. Similarly, public and social indicators may deeply affect communities who have had minimal say in formulating the criteria on which policies are measured (cf., Merry et al., 2015) and may thus lose an important institutional channel of participation. Seemingly democratizing ratings systems instantaneously available at the touch of a smart phone (e.g., product reviews, crowd 
sourced feedback) may paradoxically drive inclusion/exclusion, reconfigure interpersonal relationships, and conceal organizational control (Amirdis \& Costea, 2020). From a business ethics focus, therefore, understanding how different populations shape and are shaped by metrics is an important direction for research.

\section{Conclusion: Between Representation and Performativity}

The analytical distinction we draw above between representation (the metrics of ethics) and performativity (the ethics of metrics) is, not surprisingly, blurred in practice. To cite Goodhart's law (in Greenfield, 2017, p. 205), "when a measure becomes a target, it ceases to be a measure"-but in fact organizations blur measures and targets all the time. A performance measure is used to improve performance. A CSR disclosure is used to create a ranking. A credit score is used to determine future trustworthiness. The problem is not that the quantitative measures are inaccurate (though they may well be), rather it is that the use of such indicators in decision-making may corrupt the practice it is purportedly intended to improve (Campbell, 1979). Much of the social power of metrics comes from their use as targets, and this use is unlikely to be deterred by scholars' caveats to use measures only for their intended purposes. While these caveats should continue, we should also pay more attention to the messy world of practice, where representation and action are entangled.

In this way, our two themes related to the broader question of the link between theory and practice. How does our academic use of metrics as knowledge instruments relate to their applied use as means of coordination, management and control? How strongly should we defend the line between representing the world and changing it, or in a more pragmatist spirit, should that line remain porous? Assuming the latter, the struggle becomes one of best managing the imbrication of practical effects into our representational practices while maintaining scholarly rigor in our attempts to understand the world.

As a final point, we leave our reflection by wondering what the limits of measurement are, if any, and whether there are areas of ethical life that are best left unmeasured. If so, how should we speak of such areas in our scholarship, maintain them in our awareness, and sustain that aspect of their value that resists measure? This question broadens our scope to one that lies at the core of ethical scholarship, to the question of how one should represent in the mind what must be done in the world. For now, however, our task has been to engender discussion.

\section{References}

Aitken, R. (2017). 'All data is credit data': Constituting the unbanked. Competition and Change, 21(4), 274-300.

Amiridis, K., \& Costea, B. (2020). Managerial appropriations of the ethos of democratic practice: Rating, 'policing', and performance management. Journal of Business Ethics, 164(4), 701-713.

Austin, J. L. (1962). How to do things with words. Harvard University Press.

Bruder, I. (2020). A social mission is not enough: Reflecting the normative foundations of social entrepreneurship. Journal of Business Ethics. https://doi.org/10.1007/s10551-020-04602-5

Bruno, I., Didier, E., \& Vitale, T. (2014). Statactivism: Forms of action between disclosure and affirmation. The Open Journal of Sociopolitical Studies, 2(7), 198-220.

Butler, N., Delaney, H., Hesselbo, E., \& Spoelstra, S. (2020). Beyond measure. Ephemera, 20(3), 1-16.

Campbell, D. T. (1979). Assessing the impact of planned social change. Evaluation and Program Planning, 2(1), 67-90.

Chandler, D., \& Fuchs, C. (2019). Digital objects, digital subjects: Interdisciplinary perspectives on capitalism, labour and politics in the age of big data. University of Westminster Press.

Cho, C. H., \& Patten, D. M. (2013). Green accounting: Reflections from a CSR and environmental disclosure perspective. Critical Perspectives on Accounting, 24(6), 443-447.

Daly, A., Mann, M., \& Devitt, S. K. (2019). Good data. Institute of Network Cultures.

Desrosières, A. (1993). La politique des grands nombres: Histoire de la raison statistique. Editions la Decouvert.

Eccles, R. G., Lee, L. E., \& Stroehle, J. C. (2020). The social origins of ESG: An analysis of Innovest and KLD. Organization and Environment, 33(4), 575-596.

Ellertson, C. F., Ingerson, M. C., \& Williams, R. N. (2016). Behavioral ethics: A critique and a proposal. Journal of Business Ethics, 138(1), 145-159.

Gilles, M. (2016). Figures for what purposes? The issues at stake in the struggles to define and control the uses of statistics. In I. Bruno, F. Jany-Catrice, \& L. Touchelay (Eds.), The social sciences of quantification (pp. 149-160). Springer.

Greenfield, A. (2017). Radical technologies: The design of everyday life. Verso Books.

Greenwood, M., \& Freeman, R. E. (2017). Focusing on ethics and broadening our intellectual base. Journal of Business Ethics, 140(1), 1-3.

Greenwood, M., \& Freeman, R. E. (2018). Deepening ethical analysis in business ethics. Journal of Business Ethics, 147(1), 1-4.

Greenwood, M., \& Van Buren, H. J. (2017). Ideology in HRM scholarship: Interrogating the ideological performativity of 'New Unitarism.' Journal of Business Ethics, 142(4), 663-678.

Harrison, J. S., \& Berman, S. L. (2016). Corporate social performance and economic cycles. Journal of Business Ethics, 138(2), 279-294.

Islam, G. (2021). Business ethics and quantification: Towards an ethics of numbers. Journal of Business Ethics. https://doi.org/ 10.1007/s10551-020-04694-z

Järvinen, J., Laine, M., Hyvönen, T., \& Kantola, H. (2020). Just look at the numbers: A case study on quantification in corporate environmental disclosures. Journal of Business Ethics. https:// doi.org/10.1007/s10551-020-04600-7 onlinefirst.

Malsch, B., \& Tessier, S. (2014). Journal ranking effects on junior academics: Identity fragmentation and politicization. Critical Perspectives on Accounting, 26, 84-98. 
Marti, E., \& Gond, J.-P. (2018). When do theories become selffulfilling? Exploring the boundary conditions of performativity. Academy of Management Review, 43(3), 487-508.

Martin, K. (2019). Ethical implications and accountability of algorithms. Journal of Business Ethics, 160(4), 835-850. https:// doi.org/10.1007/s10551-018-3921-3

Mattingly, J., \& Bailey, N. (2021). Constructs and measures in stakeholder management research. In M. A. Hitt (Ed.), Oxford Research Encyclopedia of Business and Management. Oxford University Press.

Merry, S. E., Davis, K. E., \& Kingsbury, B. (Eds.) (2015). The quiet power of indicators: Measuring governance, corruption, and the rule of law. Cambridge University Press.

Mingers, J., \& Willmott, H. (2013). Taylorizing business school research: On the "one best way" performative effects of journal ranking lists. Human Relations, 66(8), 1051-1073.

Noble, S. U. (2018). Algorithms of oppression: How search engines reinforce racism. NYU Press.
Power, M. (1997). The audit society: Rituals of verification. Oxford University Press.

Ustek-Spilda, F. (2019). Statisticians as back-office policy-makers: Counting asylum-seekers and refugees in Europe. Science, Technology and Human Values. https://doi.org/10.1177/0162243919 882085

Veltri, S., \& Bronzetti, G. (2015). A critical analysis of the intellectual capital measuring, managing, and reporting practices in the nonprofit sector: Lessons learnt from a case study. Journal of Business Ethics, 131(2), 305-318.

Zyphur, M. J., \& Pierides, D. C. (2017). Is quantitative research ethical? Tools for ethically practicing, evaluating, and using quantitative research. Journal of Business Ethics, 143, 1-16.

Publisher's Note Springer Nature remains neutral with regard to jurisdictional claims in published maps and institutional affiliations. 